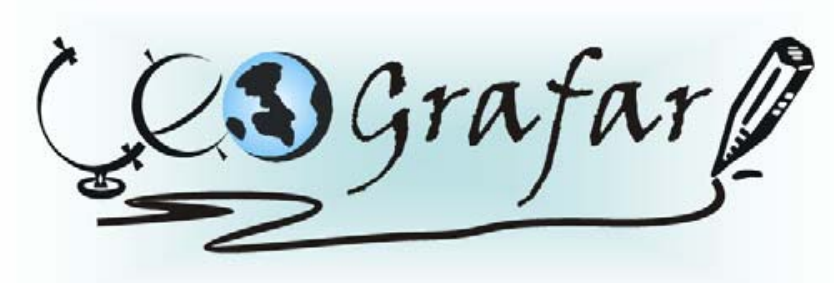

Revista Eletrônica do Programa de Pós-Graduação em Geografla - UFPR

\title{
FRAGILIDADE DE TRILHAS EM ÁREAS NATURAIS PROTEGIDAS: ESTUDO DE CASO DA RESERVA ECOLÓGICA ITAYTYBA - RPPN ${ }^{1}$
}

\author{
RONALDO FERREIRA MAGANHOTTO ${ }^{1}$; LEONARDO JOSÉ CORDEIRO SANTOS ${ }^{2}$; LUIZ CLÁUDIO DE \\ PAULA SOUZA ${ }^{3}$; MARCOS ANTÔNIO MIARA ${ }^{4}$; JAIME BARROS DOS SANTOS JUNIOR ${ }^{5}$
}

\section{RESUMO}

Os impactos socioambientais evidenciados nos centros urbanos e a necessidade de descanso e lazer das pessoas são fatores determinantes no crescimento da demanda do ecoturismo. Entretanto, tal atividade tem gerado sérios problemas ambientais devido a má utilização dos recursos naturais. O acúmulo de lixo, o desmatamento excessivo, a compactação do solo, a erosão dentre outros, são realidades inerentes à utilização dos recursos turísticos naturais. Neste contexto, priorizando a preservação do ambiente, este trabalho tem como objetivo a prevenção dos impactos provenientes da utilização de trilhas em áreas naturais. A pesquisa ocorreu na RPPN Reserva Ecológica Itaytyba, localizada no município de Tibagi, onde o ecoturismo e a educação ambiental fazem-se presentes. Fundamentado na metodologia proposta por Ross (1994), o estudo priorizou uma análise conjunta e integrada de variáveis físicas, resultando na identificação de diferentes classes de fragilidade nos traçados das trilhas existentes na área. Estes procedimentos possibilitaram a identificação de locais com diferenciados graus de susceptibilidade a degradação. Desta forma, a avaliação e a correlação destas variáveis, certificou o manejo das trilhas, além de fundamentar tecnicamente sua manutenção.

Palavras chave: Impacto Ambiental, Trilha Ecológica, Turismo.

\section{FRAGILITY OF TRACKS IN PROTECTED NATURAL AREAS: STUDY THE CASE ECOLOGICAL RESERVE ITAYTYBA - RPPN}

\begin{abstract}
The environment impacts seen on the big human centers and people's necessity of some rest and spare time are determining factors in the growth of ecotourism. However, this activity has generated some serious environment problems caused by the bad use of the natural resources. The garbage accumulation, the extreme deforestation, the ground compacting, the erosion and others are inert realities to the natural tourist resources. In this context, prioritizing the environment preservation, this paper has as objective the prevention inherent impacts to the use of tracks in natural areas. The research happened in the Itaytyba Ecological Reserve - RPPN, located in the city of Tibagi, where the ecotourism and the ambient education are always present. Based on the methodology proposal by ROSS (1994), the research prioritized a joint and integrated analysis from the physics variables, resulting in the identification of different categories of fragility in the lines. These procedures make possible the identification of places with differently susceptibility degrees to degradation. This way, the evaluation and the correlation of these variations, have certificated the handling of the tracks, beyond technical basing its maintenance.

Key words: Environment Impact, Ecological Tracks, Tourism.

\footnotetext{
2 Prof. Dr. do Programa de Pós-Graduação e Departamento de Geografia da UFPR, e-mail: santos@ufpr.br;

${ }^{3}$ Prof. Dr. do Departamento de Agronomia da UFPR, e-mail: 1csouza@ufpr.br;
}

1 Parte da dissertacão do $1^{\circ}$ autor - apresentado ao Programa de Pós Graduacãa em Geografia da UFPR.

${ }^{4}$ Doutorando do Programa de Pós-Graduação em Geografia, UFPR, e-mail: marmiara@yahoo.com.br;

${ }^{5}$ Eng. Florestal, mestrando em Ciências do Solo, UFPR, e-mail: pedologia@,hotmail.com
\end{abstract}




\section{INTRODUÇÃO}

A rotina dos grandes centros urbanos, aliada aos seus variados problemas socioambientais, contribuem para que uma parcela da população deixe tais concentrações em busca de descanso e da tranqüilidade da zona rural, realidade que abriu espaço para o crescimento de atividades turísticas em áreas naturais, como o ecoturismo.

Segundo D`amore (1993) o relevante crescimento do turismo em áreas naturais relaciona-se a dois fatores principais: a necessidade de visitar um espaço fora da situação caótica urbana, que possibilite qualidade de vida diante de um ambiente tranqüilo que alivie seu estresse, e o surgimento e o fortalecimento de uma valorização ambiental.

Entretanto, a atividade ecoturística necessita da implementação de uma série de elementos, como as trilhas, as quais favorecem a aproximação das pessoas com a natureza de maneira organizada e segura.

Segundo a EMBRATUR (1994, p. 9), “as trilhas são corredores de circulação bem definidos dentro da área protegida e através dos quais os visitantes são conduzidos a locais de grande beleza natural para observação da natureza."

Porém, se mal planejadas poderão resultar em problemas de maior amplitude como compactação e erosão dos solos, assoreamento dos rios, degradação da vegetação, entre outros (PAGANI, 1998).

Neste contexto, o planejamento e a gestão das trilhas são de extrema importância para a conservação da natureza, bem como para segurança e comodidade dos seus usuários.

Segundo Wallace (2001), as trilhas são extremamente importantes em qualquer área protegida e raramente recebem a atenção que necessitam nas unidades de conservação ou locais ecoturísticos novos ou em desenvolvimento.

Diante de tal importância o presente estudo foi realizado numa Reserva Particular do Patrimônio Natural, RPPN, denominada de Reserva Ecológica Itaytyba, localizada na Fazenda Santa Lídia do Cercadinho, situada a margem direita do Cânion Guartelá, no município de Tibagi pertencente a região fitogeográfica dos Campos Gerais (Figura 1).

A área de estudo e seu entorno regional identificam-se como um ecossistema de relevante importância devido suas características históricas, climáticas, fisiográficas, culturais e ecológicas diferenciando-se das demais regiões do estado do Paraná.

Aproveitando os expressivos recursos naturais da RPPN como atrativos turísticos, o ecoturismo vem sendo desenvolvido na área como uma alternativa importante na proteção do ambiente. 
FIGURA 1: LOCALIZAÇÃO ÁREA DE ESTUDO

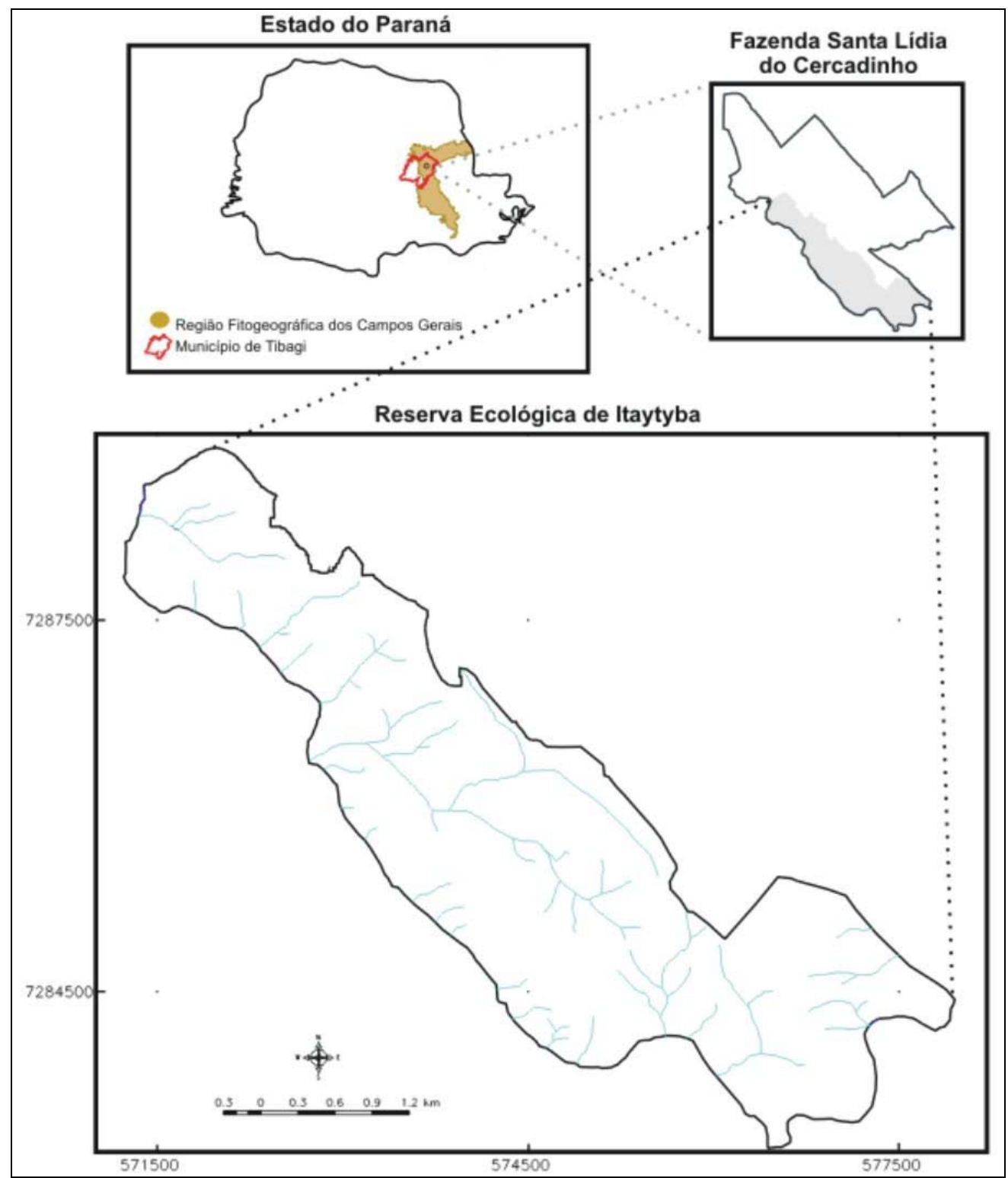

ORGANIZAÇÃO: MAGANHOTTO, R. F.

Neste sentido, a pesquisa teve como objetivo avaliar os locais de maior e ou menor susceptibilidade a degradação ambiental, fornecendo assim subsídios para um manejo adequado das trilhas.

Para atingir estes objetivos, fez-se necessário caracterizar e mapear as variáveis físicas presentes na área, seguidas de uma análise integrada das mesmas visando a identificação dos diferentes graus de fragilidade presentes nos traçados.

A seleção das classes de fragilidade teve como base os critérios preconizados por ROSS (1994), em sua metodologia de análise da fragilidade ambiental. Permitindo a determinação 
de locais com maior e menor fragilidade, fator decisivo para a determinação de locais com maior susceptibilidade ao processo erosivo, movimentos de massa e outros.

Desta forma, acredita-se que a eficiência do planejamento das trilhas está relacionada, num primeiro momento, a uma avaliação e análise conjunta dos elementos físicos possibilitando o entendimento da dinâmica natural local e dos reflexos da interferência humana.

\section{METODOLOGIA E PROCEDIMENTOS EMPREGADOS}

Ao estudar os problemas ambientais, evidencia-se que estes são frutos de uma correlação de fatores e que não podem ser entendidos de forma isolada. Desta forma, a presente trabalho teve como ponto de partida a metodologia de Ross (1991), o qual baseou-se nos preceitos Ecodinâmicos preconizados por Tricart (1977).

Para identificar o grau de fragilidade dos ambientes, Roos (1994), utiliza a correlação de variáveis físicas como os solos, a declividade e o vegetação. O cruzamento destas variáveis tem como resultado a Fragilidade Potencial e a Fragilidade Emergente. A primeira refere-se a combinação das condições de declive e de solos, enquanto a segunda é fruto da relação entre a Fragilidade Potencial com as diferentes formas de cobertura vegetal.

Assim, a fragilidade física da área de estudo resultou do cruzamento das informações referentes suas condições pedológicas, de declive e de cobertura vegetal (uso).

\section{VARIÁVEIS FÍSICAS AVALIADAS}

\section{Declividade}

Para Santos (2004), as diferentes inclinações dos terrenos em relação a um eixo horizontal condicionam e repercutem em fatores como: formas de relevo, erosão, potencialidades para uso agrícola, restrições para ocupação urbana, manejos e práticas conservacionistas.

Segundo Ross (1994) as classes de declive fornecem informações ligadas ao grau de fragilidade da área em estudo, variando conforme o percentual de declividade, conforme o apresentado na Tabela 1.

TABELA 1: GRAUS DE FRAGILIDADE DERIVADOS DA DECLIVIDADE

\begin{tabular}{lll}
\hline Valor & Classes de Fragilidade & Classes de Declividade \\
\hline 1 & Muito Baixa & Até $6 \%$ \\
2 & Baixa & De $6 \%$ a $! 2 \%$ \\
3 & Média & De $12 \%$ a $20 \%$ \\
4 & Alta & De 20 a $30 \%$ \\
5 & Muito alta & Acima de $30 \%$ \\
\hline
\end{tabular}

FONTE: ROSS (1994) 


\section{Solos}

Para Santos (2004), o solo é o suporte dos ecossistemas e das atividades humanas exercidas sobre a terra. $\mathrm{O}$ autor ressalta que a partir de sua análise é possível deduzir sua potencialidade como elemento natural, como recurso produtivo, como substrato de atividades construtivas ou como concentrador de impactos.

O levantamento semi-detalhado realizado na área de pesquisa, evidenciou-se a presença de neossolos litólicos e afloramentos rochosos. De acordo com Ross (1994), independente da sua profundidade, este solo é classificado como sendo de fragilidade muito alta.

Neste contexto Ross (1994) determinou fragilidades diferenciadas para os solo conforme o exposto na Tabela 2.

TABELA 2: GRAUS DE FRAGILIDADE DERIVADOS DOS SOLOS

\begin{tabular}{|c|c|c|}
\hline Valor & $\begin{array}{l}\text { Classes de } \\
\text { Fragilidade }\end{array}$ & Tipos de solos \\
\hline 1 & Muito Baixa & $\begin{array}{l}\text { Latossolo Bruno, Latossolo Roxo, Latossolo Vermelho escuro e } \\
\text { Vermelho amarelo textura argilosa. }\end{array}$ \\
\hline 2 & Baixa & Latossolo Amarelo e Vermelho amarelo textura média/argilosa. \\
\hline 3 & Média & Latossolo Vermelho amarelo, Argilosos, Alissolos textura \\
\hline 4 & Alta & média/argilosos \\
\hline 5 & Muito Alta & $\begin{array}{l}\text { Argissolos textura média/arenosa, Cambissolos } \\
\text { Neossolos, Organossolos }\end{array}$ \\
\hline
\end{tabular}

FONTE: ROSS (1994).

No entanto, o neossolo litólico identificado na RPPN apresentou diferentes espessuras, fato relevante na determinação de sua fragilidade, pois a variação de profundidade influencia sua dinâmica natural. Os solos mais rasos mostram-se saturados mais rapidamente quando comparados aos mais profundos, favorecendo o escoamento superficial e acarretando o processo erosivo.

Desta forma, optou-se pela criação de sub-classes da fragilidade muito alta, onde os neossolos mais profundos correspondem a fragilidade menor, enquanto os solos mais rasos e o afloramento de rocha reportam-se a uma fragilidade maior.

Seguindo a divisão sugerida, a existência de quatro sub-classes na quinta classe possibilita um melhor detalhamento na variação do grau de fragilidade dos solos da RPPN. Com base nas atividades de campo pode-se afirmar que o grau de fragilidade das sub-classes ocorrem de forma crescente, assim o neossolo litólico de menor fragilidade é o de perfil ACR seguido respectivamente do AR de $50 \mathrm{~cm}$, AR de $30 \mathrm{~cm}$ e do afloramento, conforme o apresentado na Tabela 3. 
TABELA 3: GRAUS DE FRAGILIDADE DO SOLO - RPPN.

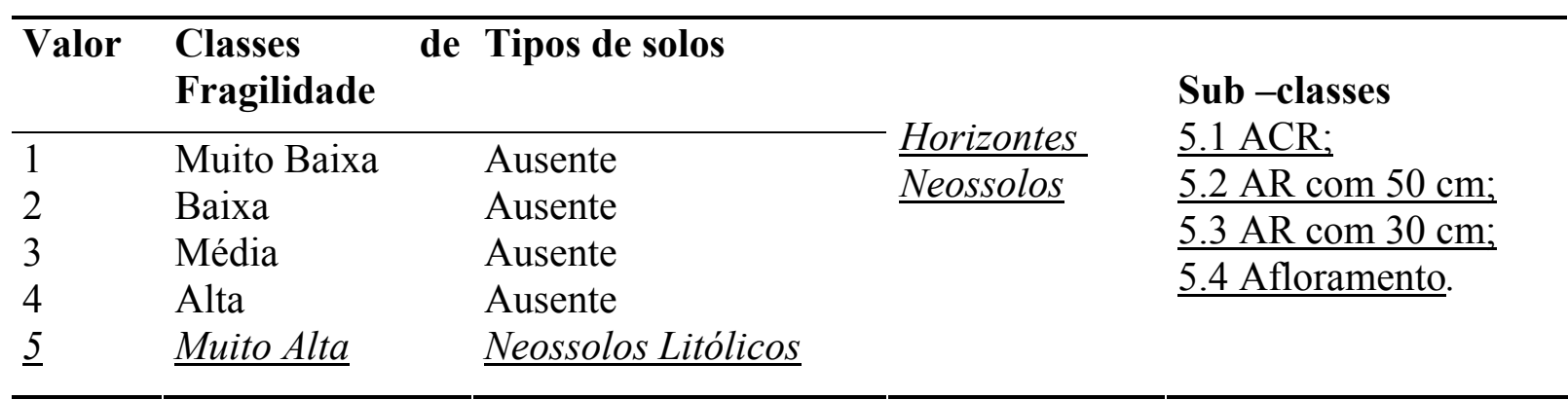

FONTE: MAGANHOTTO, R. F.

\section{Cobertura do Solo}

Segundo Santos (2004), o uso e ocupação das terras é base para o estudo do meio ambiente, por retratar as atividades humanas que podem significar pressão e impacto sobre os elementos naturais. Assim, foi proposto por Ross (1994) uma classificação de graus de proteção aos solos que variam de acordo com sua cobertura vegetal, conforme o apresentado na Tabela 4.

TABELA 4: GRAUS DE PROTEÇÃO DERIVADOS DA COBERTURA VEGETAL

\begin{tabular}{|c|c|c|}
\hline Valor & $\begin{array}{l}\text { Grau de } \\
\text { Proteção }\end{array}$ & Tipos de Cobertura Vegetal \\
\hline 1 & Muito Alta & Florestas e matas naturais, florestas cultivadas com biodiversidade \\
\hline 2 & Alta & $\begin{array}{l}\text { Formações arbustivas naturais com estrato herbáceo denso, } \\
\text { formações arbustivas densas (mata secundária, cerrado denso e } \\
\text { capoeira densa), mata homogênea de Pinus densa, pastagens } \\
\text { cultivadas com baixo pisoteio de gado, cultivo de ciclo longo }\end{array}$ \\
\hline 3 & Média & $\begin{array}{l}\text { adensado. } \\
\text { Culturas de ciclo longo em curvas de nível/terraceamento com } \\
\text { forrageiras entre ruas, pastagem com baixo pisoteio, silvicultura de }\end{array}$ \\
\hline 4 & Baixa & $\begin{array}{l}\text { eucaliptos com sub-bosques de nativas. } \\
\text { Culturas de ciclo longo de baixa densidade, culturas de ciclo curto }\end{array}$ \\
\hline 5 & $\begin{array}{l}\text { Muito Baixa } \\
\text { a nulo }\end{array}$ & $\begin{array}{l}\text { com em curvas de nível/terraceamento. } \\
\text { Áreas desmatadas e queimadas recentemente, solos exposto por } \\
\text { arado/ gradeação, solos expostos ao longo do caminhos e estradas, } \\
\text { terraplanagem, culturas de ciclo curto sem práticas } \\
\text { conservacionistas. }\end{array}$ \\
\hline
\end{tabular}

FONTE: ROSS (1994).

\section{TÉCNICAS OPERACIONAIS}

Esta pesquisa baseou-se em duas etapas complementares, uma referente as atividades de campo e a outra de laboratório. 


\section{Atividades de Campo}

As práticas de campo visaram além do reconhecimento das características físicas naturais da área, a verificação das atividades realizadas e o conhecimento das normas internas da propriedade. Posteriormente foi priorizado a certificação das informações preliminares obtidas em laboratório. Por fim, auxiliado por um sistema de posicionamento global (GPS), foi realizado a documentação fotográfica e mapeamento das trilhas. De posse destas informações verificou-se que os traçados encontram-se dispostos em três grupos. Para facilitar a discussão dos resultados e a coerência da redação, as trilhas presentes na área de estudo foram agrupadas conforme a sua seqüência e disposição resultando nos conjuntos 1, 2 e 3 .

\section{Atividades de Laboratório}

A compilação dos mapas teve como base as informações resultantes do levantamento aerofotogramétrico realizado no ano de 1980, na escala de 1:25.000 disponibilizado pela Secretária Estadual do Meio Ambiente - PR, (SEMA); das ortofotos (2001, 1:25.000) e dos arquivos digitais fornecidos pela Fundação ABC.

O processamento destas informações em ambiente de geoprocessamento, nos softwares Carta Linx e Idrisi 32, proporcionaram a compilação dos mapas temáticos referentes a localização, declividade, solos, e cobertura vegetal e no cruzamento dos três últimos para a obtenção da Fragilidade Potencial e Emergente da RPPN. O software Arc View 3.2 foi utilizado para a realização da organização e edição final dos mesmos.

A obtenção da fragilidade nas trilhas, foi obtida por meio da sobreposição e cruzamento dos traçados com o mapa de Fragilidade Emergente da RPPN, pois a correlação das variáveis físicas existente nesta Fragilidade auxilia no manejo das trilhas devido as condições de declividade, solos e cobertura vegetal apresentadas na mesma.

Considerando as condições físicas do entorno do traçado e sua interferência sob o mesmo, optou-se em ampliar a área de análise em $20 \mathrm{~m}$ de ambos os lados da trilha para uma avaliação segura da fragilidade inerente aos traçados e sua área testemunho (faixa lateral ao traçado). Outro elemento que influenciou nesta determinação foi a margem de erro, de aproximadamente $10 \mathrm{~m}$, apresentada pelo aparelho de navegação (GPS), utilizado no mapeamento das trilhas. A visualização do fluxograma, apresentado na Figura 2 facilita o entendimento da metodologia empregada na realização desta pesquisa.

Após o mapeamento das trilhas e sua sobreposição a carta de Fragilidade Emergente da RPPN, constatou-se as diferentes classes de fragilidade presentes nos conjuntos de trilhas. Estas seguiram as seguintes classificações, classe de fragilidade alta (F.A.), muito alta (F.M.A.), muito alta agravada (F.M.A.A.) e muito alta super agravada (F.M.A.S.A.). 
FIGURA 2: FLUXOGRAMA DEMONSTRATIVO DA METODOLOGIA EMPREGADA PARA A IDENTIFICAÇÃO DA FRAGILIDADE DAS TRILHAS.

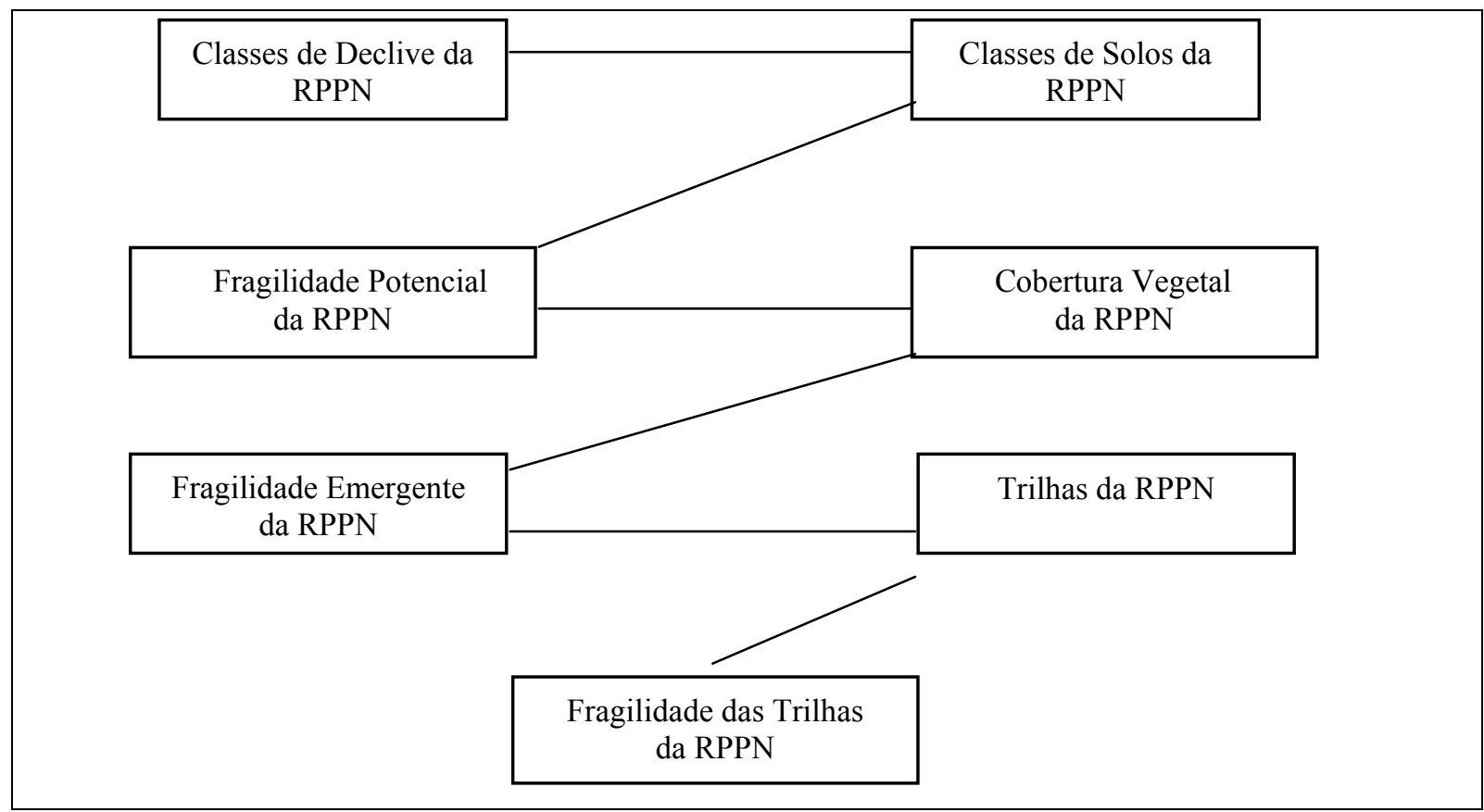

\section{RESULTADOS E DISCUSÕES}

Conforme os graus de fragilidade identificados nas trilhas e em seu entorno, pode-se afirmar que a maior porcentagem, cerca de $53 \%$ das trilhas da RPPN, encontram-se em locais de fragilidade muito alta agravada (F.M.A.A.). Em seguida, aproximadamente $22 \%$ referem-se a Fragilidade Muito Alta (F.M.A.). Enquanto 16\% e 9\% reportam-se, respectivamente, às Fragilidades Muito Alta Super Agravada (F.M.A.S.A.) e Alta (F.A.).

Neste contexto, maior parte dos traçados, ou seja, em torno de $70 \%$ dos percursos, referentes a soma das porcentagens das trilhas com F.M.A.A. e F.M.A.S.A, encontram-se em locais susceptíveis ao processo erosivo, necessitando assim, de monitoramento devido o seu grau de fragilidade.

Como já mencionado, anteriormente, para facilitar a análise e discussão dos dados, as trilhas foram agrupadas em três conjuntos. Assim, os mapas e as atividades de campo proporcionaram a identificação da distribuição das classes de fragilidade nos conjuntos de trilhas (1, 2 e 3$)$.

\section{CONJUNTO 1}

Compreendendo $22 \%$ dos traçados da reserva, este conjunto é o de menor abrangência na RPPN. A Figura 3, detalha estas informações por meio da Carta de Fragilidade no Conjuto1.

Neste conjunto, a classe de fragilidade mais expressiva é a muito alta agravada (F.M.A.A.), abrangendo $79 \%$ destes traçados. A fragilidade muito alta (F.M.A.) refere-se a 16\%, enquanto 
a fragilidade alta (F.A.) e muito alta super agravada (F.M.A.S.A.) correspondem respectivamente a $3,5 \%$ e $1,3 \%$.

A determinação para a classe de F.A. no conjunto 1 ocorreu a partir de duas correlações entre as variáveis físicas avaliadas (declive, solos, vegetação), conforme o exposto na Tabela 5.

TABELA 5 : CORRELAÇÕES FÍSICAS NA FRAGILIDADE ALTA DO CONJUNTO 1

\begin{tabular}{l}
\hline Fragilidade Alta no Conjunto 1 \\
\begin{tabular}{|l|l|l|l|}
\hline & Declividade & Solos & Vegetação \\
\hline $1^{\circ}$ Condição & 6 a $12 \%$ & AR com $50 \mathrm{~cm}$ & Cerrado \\
\hline $2^{\circ}$ Condição & 20 a $30 \%$ & ACR & Floresta \\
\hline
\end{tabular}
\end{tabular}

FONTE: MAGANHOTTO, R.F.

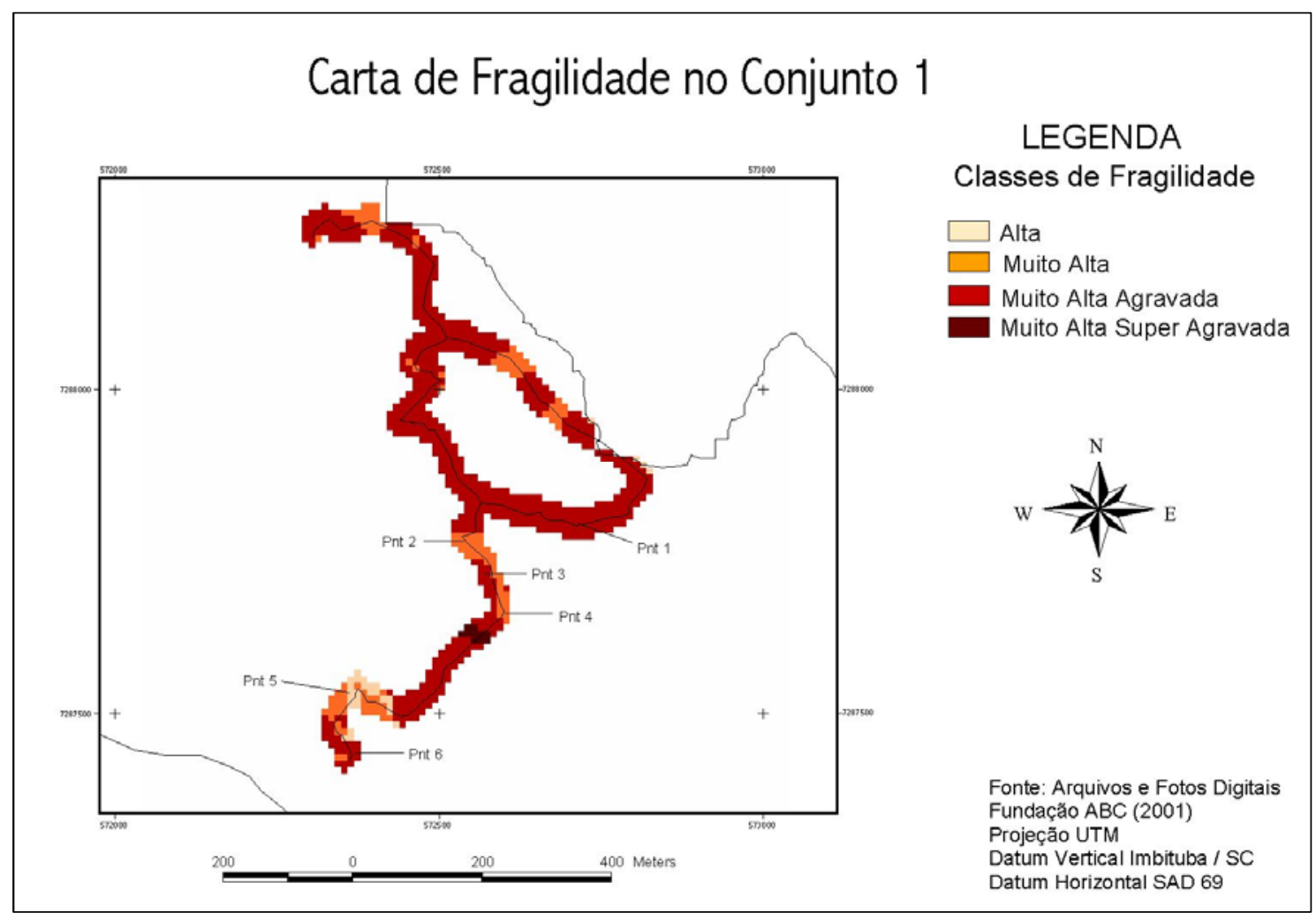

ORGANIZAÇÃO: MAGANHOTTO, R. F.

As baixas declividades que interferem no escoamento superficial e a vegetação de cerrado com alto grau de proteção, controlam e minimizam a erosão compensando a fragilidade muito alta do solo AR com $50 \mathrm{~cm}$. Além disso, conforme a subclassificação, esta condição pedológica foi a segunda de menor fragilidade na RPPN, devido sua profundidade que favorece a infiltração de água. Conforme Santos (2004), o processo erosivo, está vinculado a 
uma série de fatores subentendendo-se assim, que a presença de uma variável física de maior fragilidade não desencadeará, necessariamente, este processo, mas sim correlação destas variáveis e da ação antrópica. Neste contexto não foi evidenciado nenhum indício negativo na primeira condição.

Entretanto, a vegetação com alto grau de proteção e o solo ACR sub-classificado como sendo o de menor fragilidade na RPPN, evidenciados na $2^{\circ}$ condição não asseguram a integridade dos locais, pois a declividade neste intervalo considerada como sendo de fragilidade alta é susceptível ao processo erosivo.

Indícios de processo erosivo foram identificados nesta condição, como a exposição das raízes e o desnível no traçado, conforme o representado na Figura 3 como "pnt" 5. Pode-se afirmar que estes problemas foram condicionados pela situação pontual e potencializados pelo entorno deste local, classificados como sendo de F.M.A. devido a declividade mais acentuada.

Assim o comprimento de rampa, a serrapilheira são fatores a serem analisados nesta condição, pois diante de tal declividade estes elementos podem controlar ou potencializar a velocidade do escoamento superficial, a compactação do solo, sua erosão dentre outros.

Logo as correlações das variáveis físicas que condicionaram a determinação da classe de F.M.A. para o primeiro conjunto são variadas e resultaram em três condições, como o apresentado na Tabela 6 .

TABELA 6: CORRELAÇÕES FÍSICAS NA FRAGILIDADE MUITO ALTA DO CONJUNTO 1

Fragilidade Muito Alta no Conjunto 1

\begin{tabular}{|l|l|l|l|}
\hline & Declividade & Solos & Vegetação \\
\hline $1^{\circ}$ Condição & 12 a $20 \%$ & AR com $50 \mathrm{~cm}$ & Cerrado \\
\hline $2^{\circ}$ Condição & 0 a $6 \%$ & Afloramento & Cerrado \\
\hline $3^{\circ}$ Condição & $>$ que $20 \%$ & AR e ACR & Floresta \\
\hline
\end{tabular}

FONTE: MAGANHOTTO, R.F.

Na primeira condição a espessura do solo e o alto grau de proteção vegetal facilitando a retenção e infiltração de água somados a sua posição no topo do divisor restringindo a influência de áreas mais altas, são elementos determinantes na preservação e que compensam a declividade com grau de fragilidade média.

Logo a segunda situação, apesar de impermeável em função dos afloramentos rochosos, equilibra-se diante de uma declividade com grau de fragilidade muito baixa e de uma vegetação com alto grau de proteção.

Nestes casos, apesar das variáveis físicas estarem determinando uma F.M.A., para estas condições, não foi identificado nenhum indicio de impactos no meio natural.

Contrariando a realidade dos traçados em locais protegidos por cerrado, verificou-se para a $3^{\circ}$ condição pontos potenciais e outros com sinais de erosão. A Foto 1, referente ao "pnt 2" 
indicado na Figura 3 demonstra uma área de cobertura vegetal em transição de campo para floresta, sobre um solo AR de $50 \mathrm{~cm}$ em declividades maiores que $30 \%$.

Neste caso a floresta com alto grau de proteção, retenção e absorção não evita os indícios do processo erosivo. Além da declividade acentuada este ponto sofre a influência do escoamento superficial iniciado na parte mais alta do traçado de F.M.A.A. que se encontra impermeabilizado devido a presença dos afloramentos de rocha. Desta forma, medidas controladoras do deflúvio, de conservação da vegetação sobre o traçado, de alteração do traçado e ou de engenharia se fazem necessárias para que o deslocamento das pessoas não venha potencializar e desencadear o processo de compactação e erosão neste local. A Foto 2, recorrente ao pnt 4 da Figura 3, expõe a floresta correlacionada aos solos AR com $30 \mathrm{~cm} \mathrm{e}$ a declividades de 20 a 30\%. Retrata também indícios de erosão (vala lateral ao traçado) gerados pelo deflúvio potencializado ao longo do traçado.

FOTO 1: F.M.A. NA TRILHA

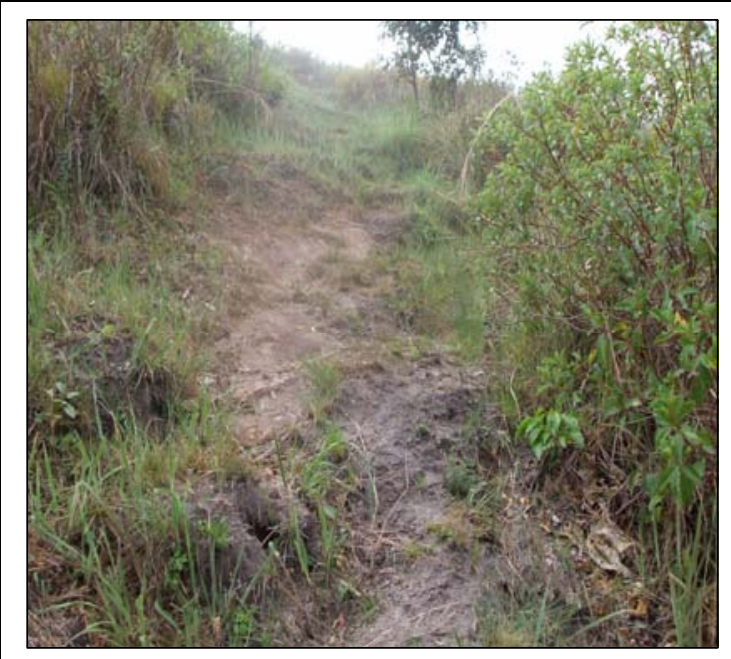

FONTE: MAGANHOTTO, R.F.
FOTO 2: F.M.A. NA TRILHA

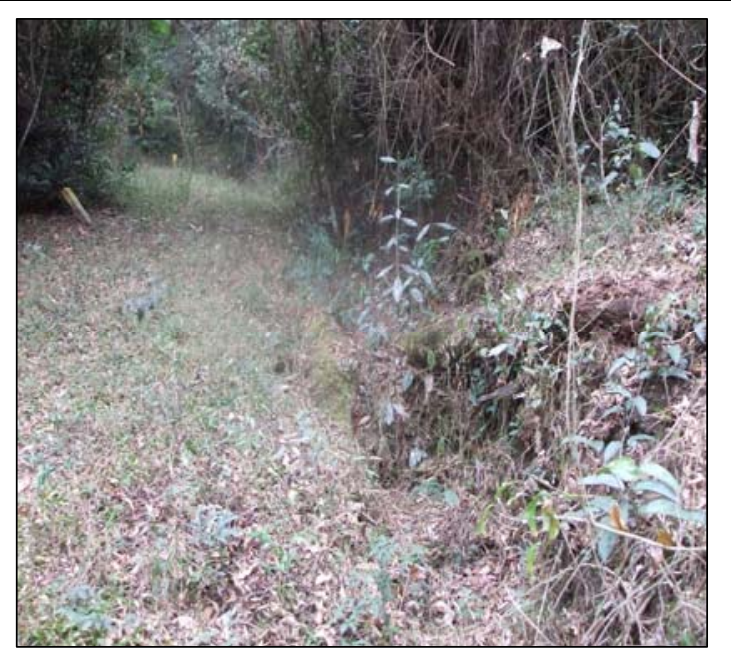

FONTE: MAGANHOTTO, R.F.

As correlações físicas que determinaram a classe de F.M.A.A. neste conjunto seguem apresentadas na Tabela 7.

TABELA 7: CORRELAÇÕES FÍSICAS NA FRAGILIDADE MUITO ALTA AGRAVADA DO CONJUNTO1

Fragilidade Muito Alta Agravada no Conjunto 1

\begin{tabular}{|l|l|l|l|}
\hline & Declividade & Solos & Vegetação \\
\hline $1^{\circ}$ Condição & $>$ que $6 \%$ & Afloramento & Cerrado \\
\hline $2^{\circ}$ Condição & $>$ que $30 \%$ & AR com $50 \mathrm{~cm}$ & Cerrado \\
\hline $3^{\circ}$ Condição & $>$ que $30 \%$ & AR com $30 \mathrm{~cm}$ & Floresta \\
\hline
\end{tabular}

FONTE: MAGANHOTTO, R.F. 
As áreas de afloramento não demonstraram problemas de erosão e ou de compactação, porém foram classificadas como sendo de fragilidade muito alta, devido os graus de fragilidade inerentes a declividade e ao afloramento.

Porém a impermeabilidade da cobertura de superfície constatada no topo do divisor sob declividades acentuadas, reflete diretamente no escoamento superficial e potencializa o processo erosivo nas áreas de menor altitude, o "pnt 1" na Figura 3 é um dos locais que sofrem este tipo de influência. Além disso pode vir comprometer o deslocamento dos visitantes devido o risco de escorregamento em determinados pontos.

A cobertura vegetal do cerrado margeando o traçado, a vegetação (roçada) mantida sobre o mesmo, e o solo de $50 \mathrm{~cm}$, são fatores controladores do escoamento superficial, da compactação e do processo erosivo que minimizaram os impactos nas declividade acima de $20 \%$.

A floresta presente neste conjunto de trilha encontra-se nas altitudes mais baixas, e associa-se a declividades maiores que $30 \%$ e a solos AR com $30 \mathrm{~cm}$ de espessura, como o exposto nas Fotos 3 e 4, recorrentes ao "pnt" 3 da Figura 3.

Neste caso, a floresta tem se mostrado fundamental na preservação do local, pois o solo raso, sub-classificado como sendo o de terceira maior fragilidade da RPPN e declividade com grau de fragilidade muito alta, são fatores condicionantes do processo erosivo. Assim, a vegetação a serrapilheira e as barreiras naturais presentes no traçado são de fundamental importância no controle do escoamento superficial e na preservação do local.

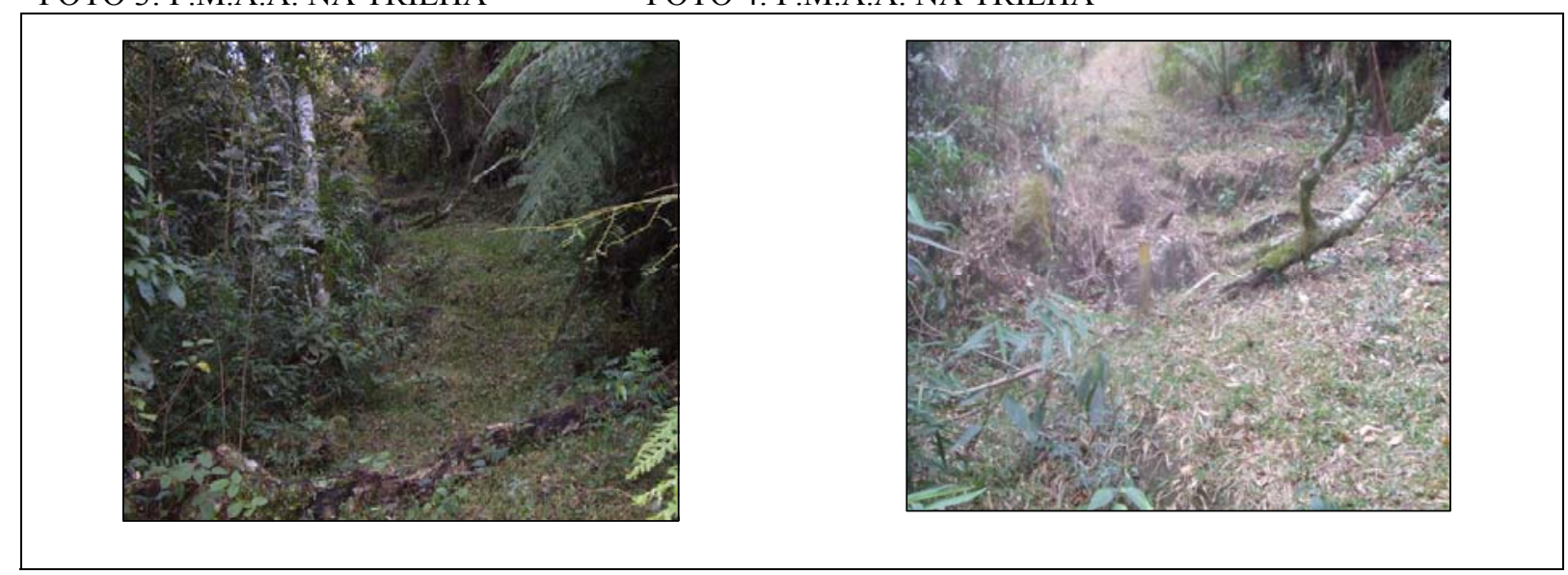

FONTE: MAGANHOTTO, R.F.

FONTE: MAGANHOTTO, R.F.

No entanto, períodos de estiagem podem vir a comprometer a vegetação existente no traçado e desencadear problemas de compactação e erosão. O efeito da estiagem na vegetação do traçado pode ser visualizado nas fotos anteriores por corresponderem a mesma trilha em épocas de índices pluviométricos opostos. A Foto 4 retrata a época mais seca, e a 3 menos seca. Evidencia-se na Foto 4 a exposição do solo devido o comprometimento vital da vegetação diante da escassez pluviométrica. Conforme Bigarella (1978), o solo quando 
exposto é mais susceptível a erosão, devido o aumento do escoamento superficial em locais onde a cobertura vegetal foi removida.

Diferentemente das fotos anteriores a Foto 5 localizada no "pnt 6" da Figura 3, retrata a trilha cortando transversalmente o declive, situação aparentemente menos problemática, porém pode ocasionar o acúmulo de água sobre o traçado, pequenos movimentos de massa agravados pelo corte da encosta e a alteração da drenagem sub-superficial para a superficial potencializando os danos inerentes ao deflúvio ou escoamento superficial nas altitudes mais baixas da vertente.

FOTO 5: F.M.A.A. NA TRILHA

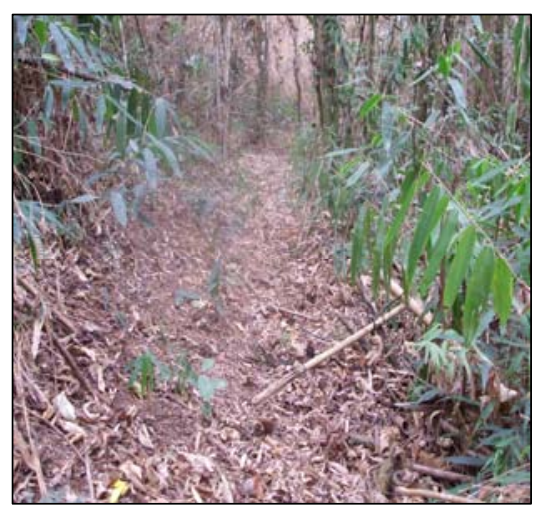

FONTE: MAGANHOTTO, R.F.

Os campos aliados aos solos AR de $30 \mathrm{~cm}$ em declividades maiores que $30 \%$ foi a correlação física neste conjunto, identificada como sendo de F.M.A.S.A.. No entanto, isto pode ser facilmente contornado com a alteração do traçado, pois o fator agravante nesta determinação reporta-se a variável pedológica

\section{CONJUNTO 2}

Os 40,5\% dos traçados da reserva sobre este conjunto, fazem deste a maior concentração de trilhas da área de estudo. As informações referentes as classes de fragilidade neste conjunto seguem apresentadas na Figura 4.

Evidencia-se neste conjunto quatro classes de fragilidade, sendo a de fragilidade muito alta (F.M.A.) predominante, presente em $41,4 \%$ do conjunto. Em seguida, encontra-se a fragilidade muito alta agravada (F.M.A.A.) com cerca de $30 \%$, a alta (F.A.) com $21,5 \%$ e por final com 7,1\% a muito alta super agravada (F.M.A.S.A.). 


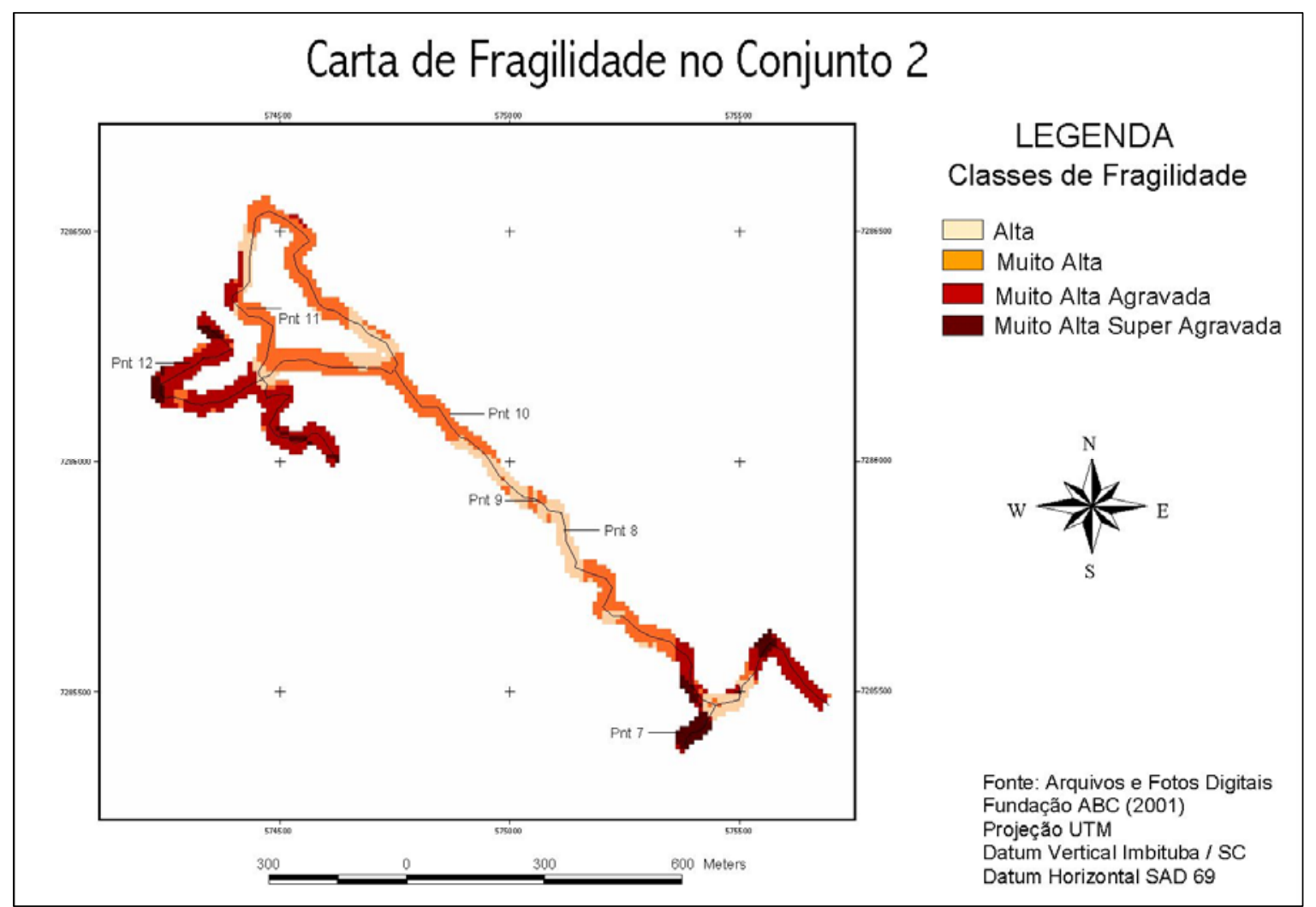

ORGANIZAÇÃO: MAGANHOTTO, R. F.

A condição determinante à classe de F.A. neste conjunto, correspondem a correlação física descrita na tabela 8 .

TABELA 8: CORRELAÇÕES FÍSICAS NA FRAGILIDADE ALTA DO CONJUNTO 2

Fragilidade Alta no Conjunto 2

\begin{tabular}{l|l|l|l}
\hline & Declividade & Solos & Vegetação \\
\hline $1^{\circ}$ Condição & 6 a $20 \%$ & AR & Floresta \\
\hline
\end{tabular}

FONTE: MAGANHOTTO, R.F.

Esta condição evidenciada no conjunto 2 é a de menor fragilidade e conseqüentemente com menor susceptibilidade aos impactos ambientais. A floresta age na interceptação e retenção de parte do índice pluviométrico controlando a saturação do solo, que aliada a declividade pouco acentuada, até $20 \%$, possibilita sua absorção inibindo o escoamento superficial.

A Carta de Declividade baseou-se em curvas de nível com 10 m de eqüidistância, assim, a veracidade das informações referentes a declividade neste intervalo foi comprometida. A partir dos campos realizados, identificou-se nesta classe de fragilidade, um ponto de maior 
susceptibilidade a erosão mediante a declividade acentuada, conforme o apresentado como "pnt 8 " na Figura 4.

O deslocamento das pessoas, neste ponto, dificulta o acúmulo da serrapilheira. Assim, o solo encontra-se diretamente expostos a pressão exercida durante o pisoteio e conseqüentemente há remoção da cobertura superficial e exposição das raízes.

Na classe de F.M.A. do conjunto 2 foram identificados pontos susceptíveis a erosão os quais encontram-se representados nas Fotos 6 e 7 e outros locais com indícios de tal processo como o evidenciado na Fotos 8. Desta forma, medidas corretivas e preventivas vem sendo estudadas e implantadas para conter tal problema.

FOTO 6: F.M.A. NA TRILHA

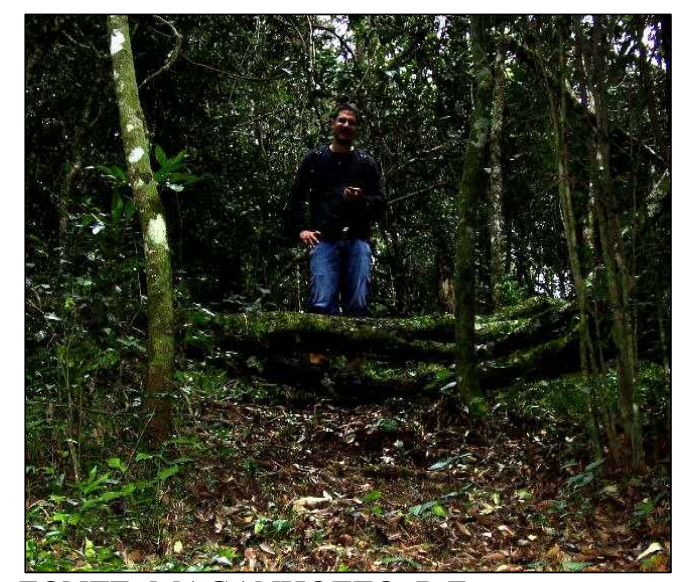

FONTE: MAGANHOTTO, R.F.
FOTO 7: F.M.A. NA TRILHA

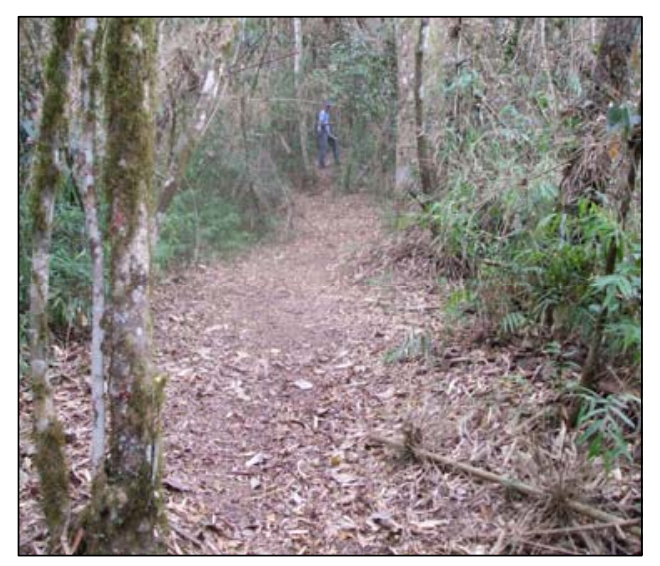

FONTE: MAGANHOTTO, R.F.

As correlações das condições de declive, solos e vegetação determinantes para esta classe encontram-se na Tabela 9.

TABELA 9: CORRELAÇÕES FÍSICAS NA FRAGILIDADE MUITO ALTA DO CONJUNTO 2

\begin{tabular}{l}
\hline Fragilidade Muito Alta no Conjunto 2 \\
\begin{tabular}{|l|l|l|l|}
\hline & Declividade & Solos & Vegetação \\
\hline $1^{\circ}$ Condição & 12 a $30 \%$ & AR com $30 \mathrm{~cm}$ & Floresta \\
\hline $2^{\circ}$ Condição & $>$ que $20 \%$ & AR com $50 \mathrm{~cm}$ & Floresta \\
\hline
\end{tabular}
\end{tabular}

FONTE: MAGANHOTTO, R.F.

A Foto 6 reporta-se ao pnt 9 da Figura 4 onde a vegetação de floresta com grau de proteção muito alto, associa-se ao solo AR de $30 \mathrm{~cm}$, de fragilidade muito alta e sub-classificado dentre os solos presentes na RPPN como sendo o de maior fragilidade, e a declividades que variam de 12 a 20\%, intervalo classificado como sendo de fragilidade média. Esta condição pedológica e de relevo fazem destes locais pontos de maior susceptibilidade ao processo erosivo, pois o solo de pequena profundidade satura rapidamente, favorecendo o escoamento 
superficial que, aliado a esta declividade, influenciará na energia cinética da água resultando nos processos erosivos.

A Foto 7, retrata a floresta sob uma condição pedológica de maior espessura (AR com $50 \mathrm{~cm}$ ) e menor fragilidade, porém com um declive mais acentuado e de maior fragilidade. Neste caso, o solo de maior espessura comporta uma maior quantidade de água até sua saturação. Diante do escoamento superficial gerado pelas chuvas, a declividade acentuada aliada a ação gravitacional colocam a água em movimento dificultando sua absorção pelo solo, potencializando o processo erosivo. Outro fator agravante identificado neste ponto e visualizado na mesma foto, refere-se ao comprimento da rampa, que devido a sua extensão, possibilita ao deflúvio ganho de energia agravando suas conseqüências na base da vertente.

As condições verificadas na Foto 8 e localizadas no pnt 10 da Figura 4 são as mesmas representadas na Foto 6. Contudo, verificou-se a existência de indícios de erosão neste ponto, conforme o visualizado no quadrante esquerdo inferior da foto. A declividade, o comprimento da rampa potencializando a velocidade da água, e a largura do traçado possibilitando um maior acúmulo e volume de água, foram fatores decisivos para este acontecimento. Diante desta situação, objetivando a contensão do processo erosivo, o escoamento foi controlado com o auxílio de barreiras naturais, como o demonstrado no quadrante superior da mesma foto.

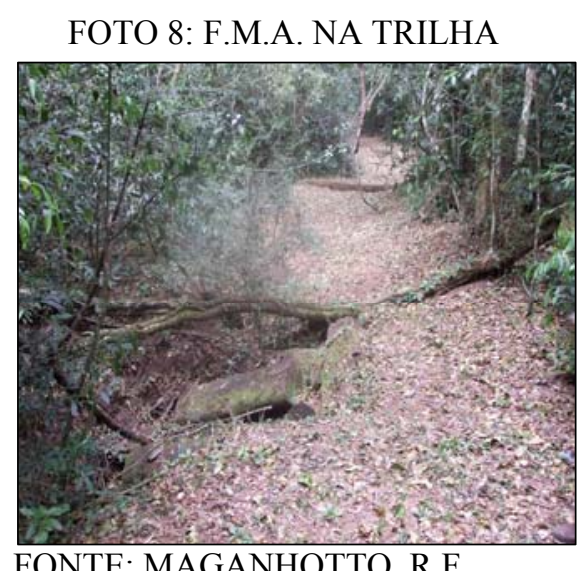

Indícios de erosão também foram constatados em uma antiga estrada utilizada pela Copel para a manutenção das torres de alta tensão da região, no entanto, o traçado da estrada foi recuperado e vem sendo utilizado como trilhas ecoturísticas contendo tal impacto. Este local é identificado na da Figura 4 como "pnt 11".

A classe de F.M.A.A. foi determinada por meio de duas combinações das variáveis físicas, as quais seguem apresentadas na Tabela 10.

TABELA 10: CORRELAÇÕES FÍSICAS NA FRAGILIDADE MUITO ALTA AGRAVADA DO CONJUNTO2

Fragilidade Muito Alta Agravada no Conjunto 2

\begin{tabular}{|l|l|l|l|}
\hline & Declividade & Solos & Vegetação \\
\hline $1^{\circ}$ Condição & 6 a $30 \%$ & AR & Campos \\
\hline $2^{\circ}$ Condição & 6 a $20 \%$ & Afloramento & Campos \\
\hline
\end{tabular}

FONTE: MAGANHOTTO, R.F. 
As declividades variando numa fragilidade entre baixa a alta e os solos AR cobertos por campos, cobertura de grau médio de proteção, não denunciaram até o momento sinais de impactos e ou de risco para os visitantes. Novamente a condição do traçado acompanhando as curvas de nível e a presença de uma vegetação (roçada) no traçado, são fatores determinantes para a conservação destas condições naturais, Foto 9 "pnt" 12 da figura 4.

FOTO 9: F.M.A.A. NA TRILHA

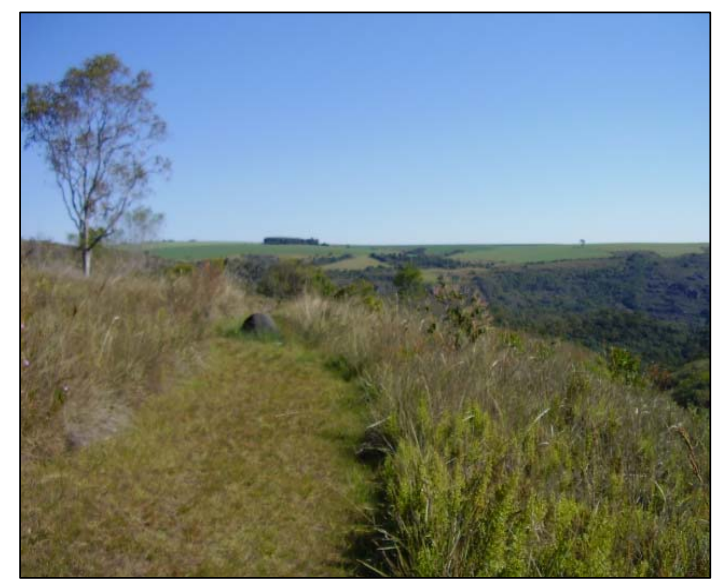

FONTE: MAGANHOTTO, R.F.

A combinação entre as variáveis físicas, referentes a classe de F.M.A.S.A., no conjunto 2, corresponde a associação das variáveis físicas descritas na Tabela 11.

TABELA 11: CORRELAÇÕES FÍSICAS NA FRAGILIDADE MUITO ALTA SUPER AGRAVADA DO CONJUNTO 2.

Fragilidade Muito Alta Super Agravada no Conjunto 2

\begin{tabular}{|l|l|l|l|}
\hline & Declividade & Solos & Vegetação \\
\hline $1^{\circ}$ Condição & $>$ que $20 \%$ & Afloramento & Campos \\
\hline
\end{tabular}

FONTE: MAGANHOTTO, R.F.

O "pnt 7" da Figura 4 registra esta condição no topo do divisor, entretanto esta mesma correlação é evidenciada em áreas de menor altitude. Quanto aos indícios de impactos registrou-se apenas uma pequena vala lateral ao traçado de altitude mais baixa, ora ocasionado pelo escoamento superficial, ora ocasionado pela impermeabilidade da cobertura de superfície presente no traçado da trilha.

Tal condição pode estar condicionando o processo erosivo em seu entorno, devido o favorecimento do escoamento superficial pela condição de relevo e de impermeabilidade da cobertura de superfície. Além disso, é importante ressaltar o risco de escorregamentos dos visitantes em situações de umidade ou acúmulo de água sob a rocha. 


\section{CONJUNTO 3}

Comparado aos outros conjuntos da Reserva, o conjunto 3 é o grupo de trilhas de extensão intermediária. Seu percentual corresponde a aproximadamente $38 \%$ dos traçados inseridos na reserva. Evidenciam-se neste conjunto três classes de fragilidade, onde a de F.M.A.A. predomina demarcando cerca de $64 \%$ das trilhas deste conjunto, a F.M.A.S.A. corresponde a $34,4 \%$, enquanto a F.M.A. delimita apenas 1,6\% deste conjunto. De posse destas informações pode-se afirmar que este conjunto enquadra-se como sendo o de maior fragilidade da RPPN. A distribuição destas informações pode ser verificada espacialmente na Figura 5.

\section{FIGURA 5: FRAGILIDADE NO CONJUNTO 3}

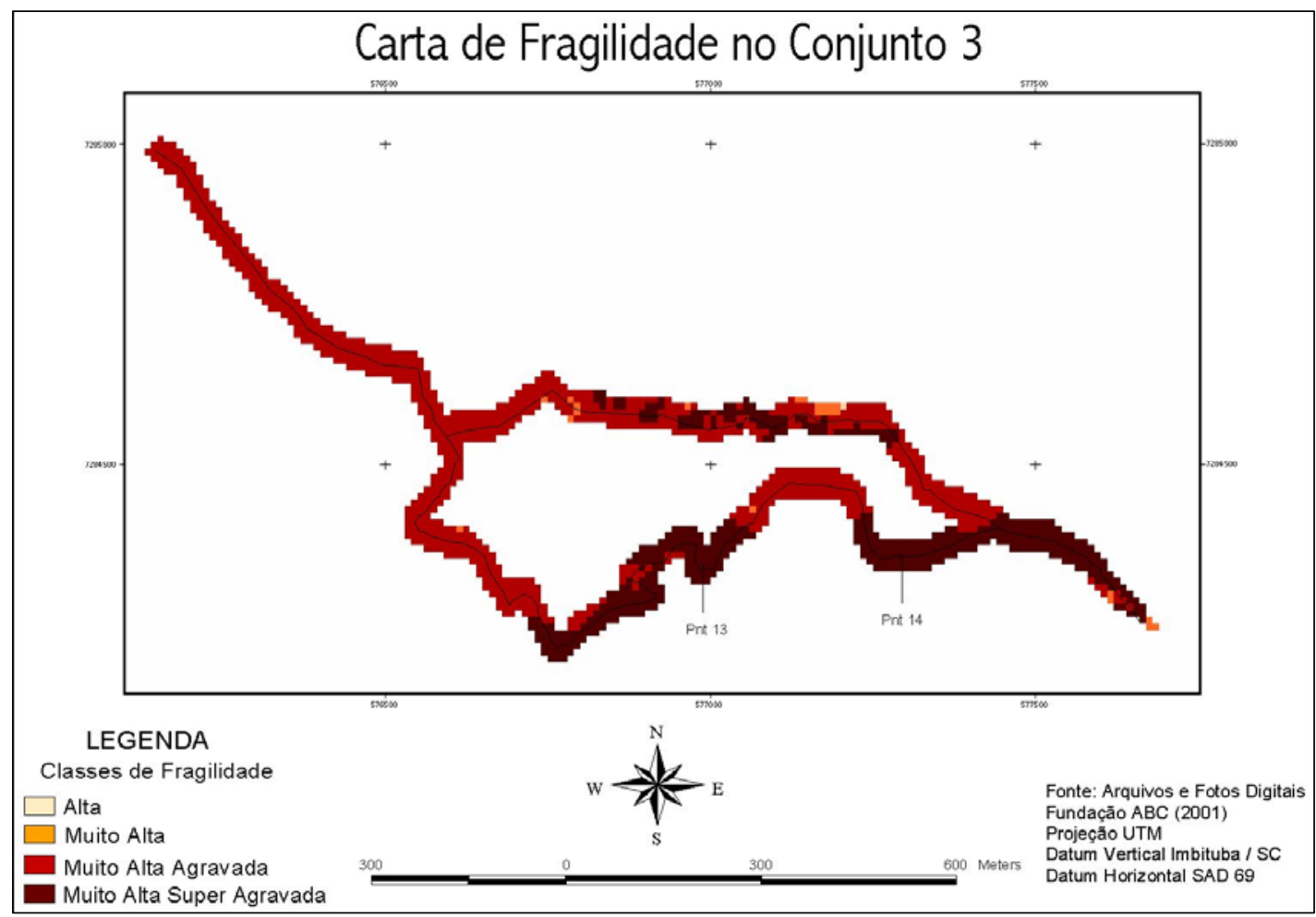

ORGANIZAÇÃO: MAGANHOTTO, R. F.

A condição física predominante na classe de F.M.A.A. reporta-se a associação das variáveis apresentadas na Tabela 12.

TABELA 12: CORRELAÇÕES FÍSICAS NA FRAGILIDADE MUITO ALTA AGRAVADA DO CONJUNTO 3.

\begin{tabular}{|c|c|c|c|}
\hline \multicolumn{4}{|c|}{ Fragilidade Muito Alta Super Agravada no Conjunto 2} \\
\hline & Declividade & Solos & Vegetação \\
\hline $1^{\circ}$ Condição & 12 a $30 \%$ & AR & Campos \\
\hline
\end{tabular}

FONTE: MAGANHOTTO, R.F. 
Ao comparar as condições físicas evidenciadas na classe de F.M.A.A. com as especificidades recorrentes a classe de F.M.A.S.A, pode-se afirmar que as áreas com declividade acima de 30 $\%$, indicadas nos pontos 13 e 14 da Figura 5 agiram como fator agravante, determinando para estes locais uma fragilidade mais alta.

Além das declividades maiores que $30 \%$, os afloramentos também de fragilidade muito alta, foram determinantes para a classe de F.M.A.S.A..

Apesar da elevada fragilidade física constatada neste conjunto de trilhas, não houve evidencias de impactos derivados da sua utilização. As condições naturais preservadas observadas no traçado e entorno desta trilha é justificada em função de sua utilização controlada e da sua condição de percurso (caminhos delineados por animais silvestres).

Os resultados obtidos na análise da Fragilidade Ambiental Física da Reserva Ecológica Itaytyba e de suas trilhas, denotaram fragilidade muito alta agravada e muito alta como predominante. Desta forma, a legitimação desta área em unidade de conservação e sua gestão restringindo a ação antrópica à utilização indireta dos recursos naturais por meio de atividades controladas e monitoradas de cunho científico, ecoturístico e de educação ambiental, contribuem decisivamente para a preservação deste ambiente.

\section{CONSIDERAÇÕES FINAIS}

Os impactos inerentes as trilhas em áreas naturais estão intimamente ligados a dinâmica natural e a forma e a intensidade de como este é utilizado. Logo, para a prevenção destes impactos e preservação de determinado ambiente, se faz necessário conhecer suas variáveis e especificidades físicas. Estas informações tendem a facilitar o entendimento do meio natural, principalmente pela identificação das correlações existentes entre as variáveis do meio físico e sua resposta diante da interferência humana. Neste contexto, a ação humana pode repercutir de duas formas, uma na prevenção e outra na potencialização dos impactos ambientais.

Desta forma, os impactos ligados as trilhas e identificados na área de estudo reportam-se a exposição do solo e de raízes e princípios erosivos, os quais já foram identificados e controlados.

Entretanto, durante a realização desta pesquisa ficou claro que os impactos ambientais recorrentes das trilhas e sua prevenção, não são apenas dependentes do grau de fragilidade evidenciado pontualmente, mas também da dinâmica natural ocorrente no traçado. Fatores como a altitude, a declividade, o comprimento de rampa, o índice pluviométrico, a permeabilidade do solo, a vegetação, suas correlações e localização agem de forma integrada apresentando diferenciadas condições resultando numa dinamicidade natural variada.

O número controlado de visitantes nas trilhas respeitando a fragilidade local, o acompanhamento dos condutores orientando e coordenando a visitação, e a presença da vegetação e da serrapilheira nos traçados minimizando o processo de compactação e erosão, são fatores contribuintes na preservação das trilhas da Reserva Ecológica de Itaytyba. 


\section{REFERÊNCIAS}

Bigarella, J. J. et al. A Serra do Mar e a Porção Oriental do Estado do Paraná. Curitiba: SEPL, 1978.

D'AMORE, L. J. “A code of ethics ande guidelines for socially na environmentally responsible tourism”. A Journal of Travel Research, 1993.

EMBRATUR, Instituto Brasileiro de Turismo. Manual de ecoturismo. Brasília, maio 1994.

PAGANI, M. I.- As trilhas interpretativas da natureza e o ecoturismo. In: LEMOS, A. I. G. (org). Turismo impactos sócio ambientais. São Paulo: ed. Hucitec,1998.

ROSS, J. L. S. Geomorfologia Ambiente e Planejamento. $2^{\circ}$ ed. São Paulo: Contexto, 1991. Análise empírica da fragilidade dos ambientes naturais e antropizados. In: Revista do Departamento de Geografia; n. 8, p. 63 - 74. São Paulo, USP, 1994.

SANTOS, R. F. dos. Planejamento ambiental: teoria e prática. São Paulo: Oficina de Textos, 2004.

TRICART, J. Ecodinâmica. Rio de Janeiro : IBGE, 1977.

WALLACE, G.N. A administração do visitante: lições do Parque Nacional de Galápagos. In: LINDBERG, K. e HAWKINS, D. (Editores). Ecoturismo um guia para planejamento e gestão. $3^{\circ}$ ed. São Paulo: SENAC, 2001. 